\title{
Analysis of Air Quality during the COVID-19 Pandemic Lockdown in Naples (Italy)
}

\section{Aerosol and Air Quality Research}

Special Issue:

Special Issue on COVID-19 Aerosol Drivers, Impacts and Mitigation $(\mathrm{X})$

\section{OPEN ACCESS}

Received: July 7, 2020

Revised: October 2, 2020

Accepted: October 6, 2020

${ }^{*}$ Corresponding Author:

boselli@imaa.cnr.it

Publisher:

Taiwan Association for Aerosol Research

ISSN: $1680-8584$ print

ISSN: 2071-1409 online

cc) Copyright: The Author(s).

This is an open access article distributed under the terms of the Creative Commons Attribution License (CC BY 4.0), which permits unrestricted use, distribution, and reproduction in any medium, provided the original author and source are cited.

\author{
Alessia Sannino1, Mariagrazia D’Emilio², Pasquale Castellano ${ }^{3}$, \\ Salvatore Amoruso ${ }^{1,4}$, Antonella Boselli ${ }^{2,3^{*}}$ \\ ${ }^{1}$ Dipartimento di Fisica "Ettore Pancini" Università di Napoli Federico II, Complesso \\ Universitario di Monte S. Angelo, I-80126 Napoli, Italy \\ ${ }^{2}$ Istituto di Metodologie per l'Analisi Ambientale, Consiglio Nazionale delle Ricerche, I-85050 \\ Tito Scalo-Potenza, Italy \\ ${ }^{3}$ ALA Advanced Lidar Applications s.r.l. Corso Meridionale 39, I-80143 Napoli, Italy \\ ${ }^{4}$ CNR-SPIN, UOS Napoli, Complesso Universitario di Monte S. Angelo, I-80126 Napoli, Italy
}

\section{ABSTRACT}

Lockdown measures applied in the aftermath of the COVID-19 pandemic spread to Italy in the period March $13^{\text {th }}-$ May $4^{\text {th }}$ strongly limited the social and industrial activities with consequent effects on the air pollution. Here we report a study on the influence of the lockdown measures on the air quality in the city of Naples (Italy). The comparison of the levels of various gaseous pollutants $\left(\mathrm{C}_{6} \mathrm{H}_{6}, \mathrm{CO}, \mathrm{NO}_{2}\right.$ and $\left.\mathrm{SO}_{2}\right)$ and particulate matter $\left(\mathrm{PM}_{10}, \mathrm{PM}_{2.5}, \mathrm{PM}_{1}\right)$ at ground level as well as of atmospheric aerosol properties registered by remote sensing techniques during the lockdown period with the values observed in the earlier months and during the same period of the previous year is used to gain interesting information on the environmental impact of the human activities. Our findings show a rather significant reduction of the pollution due to $\mathrm{NO}_{2}$ (49-62\%) in urban as well as in green suburban area, while $\mathrm{CO}$ and $\mathrm{SO}_{2}$ showed a more important reduction in urban or industrial districts of the city $(50-58 \%$ and $70 \%$, respectively). Particulate matter at ground level is also affected but to a more limited extent (29-49\%). Nevertheless, characterization of atmospheric aerosol columnar properties suggests an interesting variation of its composition. The observed features have been associated to the strong meteorological interference from Saharan Dust in the Mediterranean area also affecting the city of Naples.

Keywords: COVID-19, Air quality, Atmospheric aerosols, Particulate matter, Remote sensing

\section{INTRODUCTION}

In the beginning of the year 2020, the COVID-19 pandemic reached Europe and lockdown actions were progressively applied in various countries. In Italy, prevention and control actions to limit and reduce the epidemic effects were settled down from March $13^{\text {th }}$ to May $4^{\text {th }}, 2020$. During this period, the national quarantine significantly limited people movement except for necessity situations, specific jobs, and health issues. Besides the main aim of controlling the epidemic diffusion, at the same time, the restriction of social and industrial activities directly affected air pollution due to reduced public and private transportation and decrease in road traffic as well as partial halting or closure of several economic and industrial activities.

Satellite observations by the "Copernicus" programme of the European Commission (EU, 2020) has shown a significant drop of $\mathrm{NO}_{2}$ concentration that has been correlated to the quarantine due to the COVID-19 active in different countries. Moreover, recent studies address the variation in the air quality during lockdown periods in cities or regional areas by means of satellite observations and/or local data (Mahato et al., 2020; Nakada et al., 2020; Tobías et al., 2020; Xu et al., 2020b; Zambrano-Monserrate et al., 2020). For example, an almost two-fold reduction of $\mathrm{NO}_{2}$ and threefold decrease of particulate matter with a diameter of less than $10 \mu \mathrm{m}\left(\mathrm{PM}_{10}\right)$ was observed in the city of Barcelona (Spain) during lockdown using Copernicus and local data of atmospheric 
pollution monitoring (Tobías et al., 2020). Another study observed a decrease of $\approx 20-30 \%$ of the monthly-averaged content of particulate matter with a diameter of less than $2.5 \mu \mathrm{m}\left(\mathrm{PM}_{2.5}\right)$, in China, in February 2020 with respect to the levels registered in the same month over the previous three years (Zambrano-Monserrate et al., 2020). The impact of COVID-19 on air quality was also addressed in different cities of central China by Xu et al. (2020a, b) evidencing on February 2020 $\mathrm{a} \approx 30-60 \%$ reduction of the concentration levels of $\mathrm{PM}_{2.5}, \mathrm{PM}_{10}, \mathrm{SO}_{2}, \mathrm{CO}$, and $\mathrm{NO}_{2}$ and a slight increase of $\approx 4-14 \%$ of the $\mathrm{O}_{3}$ concentration with respect to the values observed in the same month of the previous three years 2017-2019. Satellite observational data of $\mathrm{SO}_{2}, \mathrm{NO}_{2}$ and $\mathrm{CO}$ referred to the East of China (Filonchyk et al., 2020) confirmed the air quality improvement during lockdown with average levels reduced by about $30 \%$, compared with the same period in 2019. Effects of lockdown on air quality were also reported by exploiting local data provided by monitoring stations in India (Mahato et al., 2020; Sharma et al., 2020). Comparing the levels of particulate matter and gaseous pollutants (e.g., $\mathrm{NO}_{2}, \mathrm{CO}, \mathrm{SO}_{2}, \mathrm{O}_{3}$ ) registered during lockdown with those observed either in the same time period of previous years or in the pre-lockdown phase, the analyses evidenced that $\mathrm{PM}_{2.5}$ and $\mathrm{PM}_{10}$ were reduced by $\approx 40 \%$ and $\approx 50-60 \%$, whereas pollutants like $\mathrm{NO}_{2}$ and $\mathrm{CO}$ decreased by $\approx 50 \%$ and $\approx 30 \%$ in one study (Sharma et al., 2020) and by $\approx 20 \%$ and $\approx 10 \%$ in another one (Mahato et al., 2020), respectively. Similarly, the variation of $\mathrm{NO}, \mathrm{NO}_{2}$ and $\mathrm{CO}$ concentrations measured by four air monitoring stations in the city of São Paulo in Brazil during a partial lockdown related to COVID-19 also demonstrates considerable reduction (>50\%) when compared with the monthly-averaged values registered in the previous five years (Nakada et al., 2020). When ozone was also registered, an increase of the $\mathrm{O}_{3}$ level was observed probably correlated to the nitrogen oxides reduction (Chameides et al., 1992; Sillman, 1999). A study conducted in Iran (Broomandi et al., 2020) highlighted that unfavourable meteorological conditions as a combination of reduced rainfall and relative humidity and increased temperature can hinder pollutant dispersion increasing the aerosol optical depth in the atmosphere during lockdown. This result agrees with the observations performed in Tehran by Faridi et al. (2020) that reported higher concentrations of both $\mathrm{PM}_{2.5}(20.5 \%)$ and $\mathrm{PM}_{10}(16.5 \%)$ during lockdown.

Notwithstanding a general observation of improvement in the air quality during lockdown, the studies reported above also address a striking variability of the resulting effects that might be strictly related to specific characteristics and climatological features of the area under study. This, in turn, makes timely and useful an accurate analysis of the changes induced on the air quality by the dramatic break in the social and economic life of a city or country induced by the COVID19 pandemic. In fact, such an analysis can allow clarifying the possible influences of human and natural effects on air quality in any given region thus providing relevant information for improved strategic approaches to environmental protection and health.

Here we report on the variations in air quality in the city of Naples $\left(40,838^{\circ} \mathrm{N}, 14,183^{\circ} \mathrm{E}\right)$ during the COVID-19 lockdown in Italy. The analysis is based on data provided by ground-based air monitoring city stations for the gaseous pollutants $\left(\mathrm{C}_{6} \mathrm{H}_{6}, \mathrm{CO}, \mathrm{NO}_{2}\right.$ and $\left.\mathrm{SO}_{2}\right)$ and particulate matter $\left(\mathrm{PM}_{10}, \mathrm{PM}_{2.5}\right)$, on the measurements of $\mathrm{PM}\left(\mathrm{PM}_{10}, \mathrm{PM}_{2.5}, \mathrm{PM}_{1}\right)$ by a local optical particle counter (OPC) as well as on atmospheric aerosols properties provided by ground based remote sensing over the city by a sun photometer of the Aerosol Robotic Network (AERONET) operative at our laboratory. Anticipating our results, ground level measurements mainly evidence a significant reduction of $\mathrm{NO}_{2}$ emission in urban and industrial city districts and less consistent variation of PM, which are likely induced by the limitations due to the lockdown. Moreover, characterization of atmospheric aerosol through AERONET sun photometer measurements evidence striking changes that can be ascribed to a variation of their composition due to the changes induced in the social and industrial activities.

\section{METHODS}

Naples is the largest town in southern Italy and capital of the Campania region, with a city population of about 960000 people and the administrative center of a metropolitan area with 3 million inhabitants (ISTAT 2019, https://www.istat.it/it/). It is located halfway between the Vesuvius volcano and the volcanic area of the Phlegraean fields and overlooks the Tyrrhenian sea. Besides anthropogenic factors influencing the air quality, for its geographical location, the 
city is strongly influenced by the Mediterranean Sea and the air mass circulation coming from south with periodic transport of Saharan dust (SD). Thus, it can offer a remarkable case study to gain information about the possible effects of the various human and natural factors affecting the city air quality.

Data from the eight air quality stations located in various points in the City of Naples (see Fig. 1), made available by the agency for environment of Campania Region (ARPAC, 2020), were gathered to assess the levels of $\mathrm{C}_{6} \mathrm{H}_{6}$ (Benzene), $\mathrm{CO}, \mathrm{NO}_{2}$, and $\mathrm{SO}_{2}$, as well as of $\mathrm{PM}_{2.5}$ and $\mathrm{PM}_{10}$ Prior to the study, a comparative analysis of the data provided by the air quality stations was carried out assessing the agreement between the trends observed for the registered parameters. Then, four representative stations were considered to assess the effect of the lockdown on the air quality in different areas of the city. Two sampling stations located in two urban parks (see Fig. 1), one in the Virgiliano Park (VP) and the other in the park surrounding the Astronomic Observatory $(\mathrm{AO})$, were considered as representative of areas with a negligible influence of industrial and traffic emissions. In fact, VP is a large green area $\left(92000 \mathrm{~m}^{2}\right)$ located on the hill of Posillipo $\left(40.830^{\circ} \mathrm{N}, 14.218^{\circ} \mathrm{E}, 150 \mathrm{~m}\right.$ a.s.l.) overlooking the Gulf of Naples, hence rather isolated and far from the city center, whereas $\mathrm{AO}$ is situated in a suburban part of the city on Capodimonte hill $\left(40.862^{\circ} \mathrm{N}, 14.255^{\circ} \mathrm{E}, 150 \mathrm{~m}\right.$ a.s.I.). Both stations monitor five pollutants (i.e. $\mathrm{C}_{6} \mathrm{H}_{6}, \mathrm{CO}, \mathrm{NO}_{2}$, $\mathrm{PM}_{2.5}, \mathrm{PM}_{10}$ ), whereas the VP station also probes $\mathrm{SO}_{2}$. As a typical station influenced by the urban traffic, we selected the one located at National Museum (NM) in the historic city center of Naples (see Fig. 1). The NM station is equipped with sensors monitoring five pollutants $\left(\mathrm{C}_{6} \mathrm{H}_{6}, \mathrm{CO}, \mathrm{NO}_{2}\right.$, $\mathrm{PM}_{2.5}, \mathrm{PM}_{10}$ ). Finally, the sampling station situated in the heavily industrialized area of S. Giovanni a Teduccio (Napoli) at Argine Street (AS) close to refinery plants, fuel tanks and commercial harbour is considered. This sampling station monitors six pollutants $\left(\mathrm{C}_{6} \mathrm{H}_{6}, \mathrm{CO}, \mathrm{NO}_{2}, \mathrm{PM}_{2.5}, \mathrm{PM}_{10}\right.$, $\mathrm{SO}_{2}$ ).

The four sampling stations illustrated above allow assessing the possible influence of the different local environments typically affected by different emission sources: VP and AO provide a kind of background conditions while the others (MN and AS) are more sensitive to industrial activities and/or urban traffic. For these four reference stations, the daily averaged ( $24 \mathrm{~h}$ ) measurements were analyzed for the period of January, February, March and April 2020 aiming

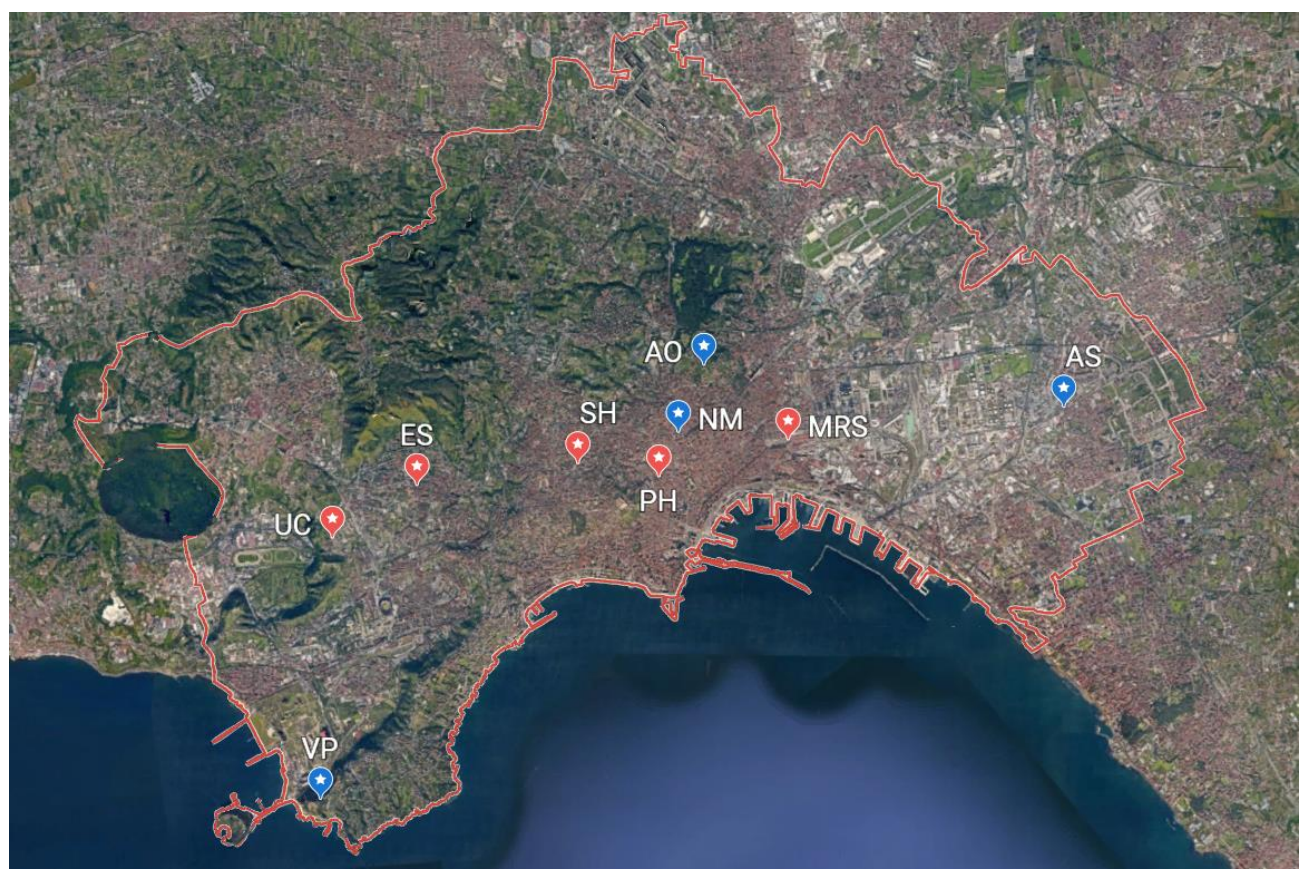

Fig. 1. Map of the City of Naples with the indication of the location of the eight air sampling stations and Optical Particles Counter at the University Campus. VP = Virgiliano Park; ES = Epomeo Station; $\mathrm{SH}=$ Santobono Hospital; NM = National Museum; AO = Astronomic Observatory; MRS = Main Railway Station; PH = Pellegrini Hospital; AS = Argine Street; UC = University Campus. The four representative stations are reported in blue. 
at assessing changes due to the lockdown starting on March 13th, 2020. Moreover, the average level of the pollutants registered in the same months in the previous year 2019 was also considered for the sake of comparison.

Concentration of PM was also measured by a ground-based Optical Particle Counter (OPC Dust monitor EDM164 GRIMM) operative at the Department of Physics of the University of Naples "Federico II" $\left(40.838^{\circ} \mathrm{N}, 14.183^{\circ} \mathrm{E}, 118 \mathrm{~m}\right.$ a.s.l. - see Fig. 1). This OPC provides measurements of the $\mathrm{PM}_{10}, \mathrm{PM}_{2.5}$ and $\mathrm{PM}_{1}$ (diameter of less than $1 \mu \mathrm{m}$ ) fraction with an integration time of 5 minutes. Daily averaged OPC measurements were contrasted with the values provided by the nearby ARPAC station located at Epomeo Station (ES - see Fig. 1) obtaining a correlation coefficient of 0.96 and 0.95 for $\mathrm{PM}_{2.5}$ and $\mathrm{PM}_{10}$, respectively. Hence, the OPC was considered as reference for the area of the city where the University Campus is located because it provides also information on the $\mathrm{PM}_{1}$ fraction, thus allowing one to gain insights on the finer $\mathrm{PM}$ fraction at ground, not measured by the ARPAC stations. Finally, columnar properties of atmospheric particle for the period of interest to the present study were obtained by means of a dual polarization and triple mode (sun, sky, lunar) photometer (CIMEL CE318TS-M), operative in the AERONET network. AERONET is a network of globally distributed ground-based remote sensing systems providing long-term and continuous observations of aerosol optical, microphysical and radiative properties for aerosol research (Holben et al., 1998). The photometer is in operation since 2016 at our laboratory situated in the Center for Metrological and Technological Services of University of Naples "Federico II" (CeSMA - $40.837^{\circ} \mathrm{N}, 14.307^{\circ} \mathrm{E}, 50 \mathrm{~m}$ a.s.l.). It provides direct solar irradiance measurements at different wavelengths covering UV, visible and near-infrared spectral range ( $340 \mathrm{~nm}, 380 \mathrm{~nm}, 440 \mathrm{~nm}, 500 \mathrm{~nm}, 675 \mathrm{~nm}, 870 \mathrm{~nm}, 1020 \mathrm{~nm}$ and $1640 \mathrm{~nm}$ ). Spectral aerosol optical depth (AOD), inversion products, and precipitable water obtained after data processing with inversion algorithms (Dubovik and King, 2000; Holben et al., 2001; Giles et al., 2019) are readily accessible at the AERONET website (https://aeronet.gsfc.nasa.gov/). The aerosol data provided by AERONET were considered here in order to address the total column loading and the size variability of the atmospheric aerosol present over Naples and retrieve further information on its physical characteristics. In fact, the remote sensing aerosol characterization offered by the sun photometer data allows further clarifying the properties of the PM and their possible variation. Moreover, air mass back-trajectories based on the HYSPLIT dispersion model developed by NOAA Air Resources Laboratory's (ARL), and provided by AERONET, were used to define source region of the observed atmospheric aerosol. Back-trajectories were supported by the $\mathrm{NMMB} / \mathrm{BSC}$-Dust daily forecasts of dust concentration profiles, provided by the Barcelona Supercomputing Center (www.bsc.es/ess/bsc-dust-daily-forecast/), in order to assess the possible influence of a Saharan Dust contribution to the observed PM variation.

\section{RESULTS AND DISCUSSION}

Here we discuss the influence of the lockdown on air quality parameters measured at the ground with the OPC and the four reference sampling stations as well as the atmospheric aerosol properties registered by the sun photometer both for diurnal (solar) and nocturnal (lunar) measurements. By considering that the lockdown became effective in the Campania Region on March $13^{\text {th }} 2020$, the investigated first quarter of year 2020 (January-April) is divided in the following two different temporal intervals: i) pre-lockdown: January $1^{\text {st }}$-March $12^{\text {th }}, 2020$; ii) lockdown: March $13^{\text {th }}-$ April $30^{\text {th }}, 2020$. Besides the variations of the measured parameters in the two periods, indicated hereafter as $\mathrm{P}$ (Pre-lockdown) and L (Lockdown), whenever appropriate, we will also compare the data with corresponding values registered in the previous year 2019 in the same periods. Although in the year 2019 there were no limitations to social and industrial activities, for the sake of consistency, the data will be presented separated in the two periods also in this last case.

First, we will illustrate the results of ground level measurements. Then, we will discuss the characteristics of the atmospheric aerosol obtained by the sun photometer.

\subsection{Ground Level Measurements}

In this section, we present the analysis of the effect of the lockdown on the concentration of 
both PM and gaseous pollutants ground level registered by the four representative sampling station (AO, AS, MN, VP) and the OPC located at the University Campus (UC). The variations observed for the PM and the presentation of the changes evidenced by the gaseous pollutants are illustrated hereafter.

The four sampling stations of the air quality monitoring network of Campania Region provide the daily average mass concentrations of $\mathrm{PM}_{2.5}$ and $\mathrm{PM}_{10}$, whereas the OPC measures real time mass concentration of $\mathrm{PM}_{1}, \mathrm{PM}_{2.5}$ and $\mathrm{PM}_{10}$ with a time resolution variable between 1 minute and 1 day. Measurement of $\mathrm{PM}_{1}$ by the OPC allows also gaining information on the finest fraction of the PM at ground complementing the data provided by the ARPAC sampling stations. OPC data reported hereafter were acquired every 5 minutes, but they were also daily averaged for the sake of consistency.

As an example of the PM variability, Fig. 2 reports daily averaged values of the PM mass concentration $\left(\mu \mathrm{g} \mathrm{m}^{-3}\right)$ monitored continuously by the OPC from January $27^{\text {th }}$ to April $30^{\text {th }}, 2020$. The data of Fig. 2 are characterized by significant day by day oscillations with daily values ranging from 6 to $54 \mu \mathrm{g} \mathrm{m}{ }^{-3}\left(\mathrm{PM}_{10}\right)$, from 3 to $34 \mu \mathrm{g} \mathrm{m} \mathrm{m}^{-3}\left(\mathrm{PM}_{2.5}\right)$ and from 2 to $31 \mu \mathrm{g} \mathrm{m}{ }^{-3}\left(\mathrm{PM}_{1}\right)$ in the whole measurement period. Mean values of $\mathrm{PM}_{10}, \mathrm{PM}_{2.5}$ and $\mathrm{PM}_{1}$ mass concentration resulted $(17 \pm 1) \mu \mathrm{g} \mathrm{m}^{-3},(12.3 \pm 0.9) \mu \mathrm{g} \mathrm{m}^{-3}$ and $(9.6 \pm 0.9) \mathrm{g} \mathrm{m}^{-3}$ during Pre-lockdown and $(21 \pm 1) \mu \mathrm{g} \mathrm{m}^{-3}$, $(15 \pm 1) \mu \mathrm{g} \mathrm{m}^{-3}$ and $(13 \pm 1) \mu \mathrm{g} \mathrm{m}^{-3}$ during Lockdown, respectively. Moreover, the daily variability of the PM concentration at ground highlights several intense peaks due to an extensive occurrence of Saharan Dust (SD) transport events influencing the PM concentration in the city of Naples; most of the peaks are measured during Lockdown from March $18^{\text {th }}$ to April $23^{\text {rd }}$. In fact, due to its geographical location overlooking the Mediterranean Sea towards the African coast, Naples and more generally Southern Italy are very often reached by air mass coming from the Sahara Desert. In this respect, it is worth noticing that SD events are typically more frequent during the period corresponding to lockdown in the year 2020 (tinted in grey in the figure) due to seasonal effects (Pisani et al., 2011). In order to highlight possible contributions due to anthropogenic activities, crossed analysis of air-mass back-trajectories and daily. forecast of dust concentration profiles over the area of interest were exploited carefully identifying the days unaffected by SD events, and only those data were considered in the analyses illustrated hereafter.

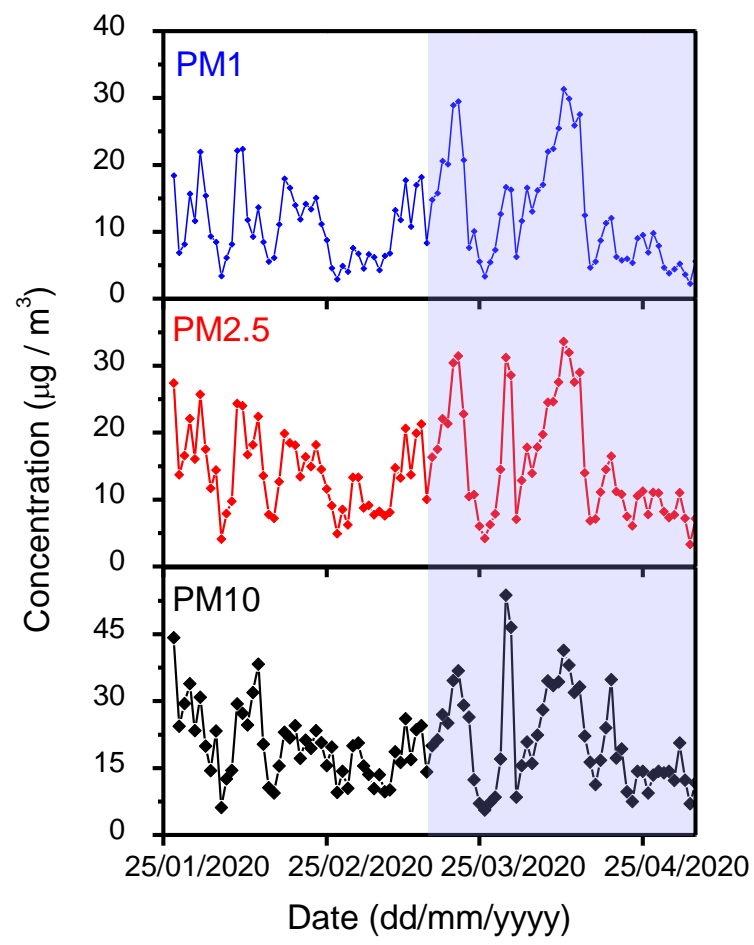

Fig. 2. Daily averaged values of the $P M$ mass concentration $\left(\mu \mathrm{g} \mathrm{m}^{-3}\right)$ monitored continuously by the OPC from January $27^{\text {th }}$ to April $30^{\text {th }}, 2020$. The shaded are tinted in light blue indicates the lockdown period. 
The daily averaged PM measurements provided by the 4 sampling stations and the OPC in absence of SD events were used to estimate a mean indicator of the PM concentration for the period preceding the lockdown $(\mathrm{P})$ and during the lockdown (L). For the sake of comparison with a period free from the effects of the limitation due to the pandemic, the data registered by the city sampling stations in the same two periods of the year 2019 are listed in Table 1, whereas the results for the year 2020 are summarized in Table 2 . In the Tables, the standard error is reported as a measure of the uncertainty of the mean value (Taylor, 1982).

Prior to discussing the data, we would like to recall that VP and AO sampling stations are located in a large green area and in a suburban park, respectively, thus they can be considered as representative of city districts weakly affected by human activities. On the other hand, NM is more descriptive of an urban area located in the very city center, whereas AS is illustrative of an urban part with a heavy industrial influence. The last column in Table 2 reports the data provided by the OPC operative in the University Campus located in a suburban, densely populated city quarter, but in a reserved access area.

Considering first the data of Table 1, the PM content in the year 2019 displays an almost stationary behavior for the suburban $A O$ and a decrease for the background reference VP and the urban $N M$ stations $\left(\mathrm{PM}_{10}\right.$ variation $\approx 20 \%$ ) and a more marked reduction ( $\mathrm{PM}_{10}$ variation $\approx 35 \%$ ) for the urban/industrial sampling station of AS for the periods preceding and following the date of March $13^{\text {th }}$ 2019, which corresponds to the day of the lockdown started in Naples in 2020. These changes might be suggestive of typical variations occurring in a such period of the year due to seasonal and/or meteorological factors. For instance, the first quarter of the year corresponds to the progressive passage from winter to spring and in Naples the residential heating systems, which can contribute by values ranging from few up to ten percent to $\mathrm{PM}_{10}$ production in typical European cities when biomass burning is used (Amato et al., 2016). These heating systems are typically stopped on March $31^{\text {st }}$ in Naples, possibly inducing a change between the two periods. Besides industrial activities, other important factors influencing PM are vehicle traffic due to both exhaust and resuspension of road dust as well particulate of natural origin as sea salts for a coastal city as Naples, to quote some, that in the year 2019 are not subject to any lockdown influence. Passing to year 2020, the data of Table 2 show a somewhat smaller concentration of PM in the lockdown phase for NM and AS stations. In this respect, it is worth noticing that in 2020 there has been an extension of the use of residential heating systems till half of April, due to the occurrence of temperatures below the seasonal average and the sanitary emergency forcing people staying home. The pronounced reduction observed for the NM $(\approx 30 \%)$ and AS $(\approx 50 \%)$ is suggestive of a contribution to PM reduction in the urban and industrial areas induced by the lockdown phase. The OPC data, instead, seem to not evidence any significant variation of the PM concentration, similarly to AO and VP.

The PM data above reported clearly indicate a seasonal effect on the PM burden in the city of

Table 1. Mean values of the PM concentration $\left(\mu \mathrm{g} \mathrm{m}^{-3}\right)$ registered by sampling stations located at the four reference city points (VP, AO, NM, AS) for the period preceding the lockdown (P) and during the lockdown (L) for the year 2019.

\begin{tabular}{|c|c|c|c|c|c|c|c|c|}
\hline Station & & VP & & O & & & & S \\
\hline Period (P/L) & $\mathrm{P}$ & $\mathrm{L}$ & $P$ & $\mathrm{~L}$ & $\mathrm{P}$ & $\mathrm{L}$ & $\mathrm{P}$ & $\mathrm{L}$ \\
\hline $\mathrm{PM}_{10}$ & $19 \pm 1$ & $15 \pm 1$ & $23 \pm 2$ & $25 \pm 1$ & $28 \pm 2$ & $22 \pm 1$ & $36 \pm 3$ & $23 \pm 1$ \\
\hline $\mathrm{PM}_{2.5}$ & $12 \pm 1$ & $9.4 \pm 0.7$ & $13 \pm 1$ & $16 \pm 3$ & $18 \pm 1$ & $11 \pm 1$ & $26 \pm 3$ & $13 \pm 1$ \\
\hline
\end{tabular}

Table 2. Mean values of the PM concentration $\left(\mu \mathrm{g} \mathrm{m}^{-3}\right.$ ) registered by sampling stations located at the four reference city points (VP, AO, NM, AS) and by the OPC at the university campus (UC) for the period preceding the lockdown (P) and during the lockdown (L) for the year 2020.

\begin{tabular}{|c|c|c|c|c|c|c|c|c|c|c|}
\hline Station & & $P$ & & 0 & & $\mathrm{M}$ & & & & \\
\hline Period (P/L) & $\mathrm{P}$ & L & $\mathrm{P}$ & L & $P$ & L & $\mathrm{P}$ & L & $P$ & $\mathrm{~L}$ \\
\hline $\mathrm{PM}_{10}$ & $13 \pm 1$ & $18 \pm 2$ & $34 \pm 2$ & $30 \pm 2$ & $31 \pm 2$ & $22 \pm 2$ & $51 \pm 5$ & $27 \pm 3$ & $19 \pm 1$ & $23 \pm 2$ \\
\hline $\mathrm{PM}_{2.5}$ & $7 \pm 1$ & $12 \pm 1$ & $17 \pm 2$ & $15 \pm 1$ & $21 \pm 2$ & $15 \pm 2$ & $37 \pm 4$ & $19 \pm 2$ & $14 \pm 1$ & $17 \pm 2$ \\
\hline $\mathrm{PM}_{1}$ & - & & - & & - & & - & & $10.7 \pm 0.9$ & $16 \pm 2$ \\
\hline
\end{tabular}


Naples, which is characterized by a typical reduction in the range (20-35)\% for urban and industrial areas as the values of the year 2019 indicate. As for year 2020, we observe a more marked change passing from the pre-lockdown to the lockdown phase with a further reduction of the order of (10-15)\% likely induced by the limitations, besides the fact that residential heating was extended on a longer period. The observed variations for urban and traffic areas are rather consistent with those observed in Barcelona (Tobías et al., 2020), but significantly lower than those reported by studies carried out in India, where a PM reduction larger than $50 \%$ was reported nationwide (Sharma et al., 2020), for the megacity of Delhi (Mahato et al., 2020) and for central China (Xu et al., 2020a, b). This difference is likely due to different geographical characteristics of the regions and the variations in the technological systems used for vehicles engines, heating systems and industry.

The four air quality sampling stations monitor the daily average mass concentration of various pollutants. In particular, we consider here $\mathrm{C}_{6} \mathrm{H}_{6}, \mathrm{CO}$ and $\mathrm{NO}_{2}$ that are sampled by all four stations, whereas VP and AS also provide $\mathrm{SO}_{2}$. The data are summarized in Table 3 for both years 2019 and 2020 separated for the period preceding the lockdown (P) and for the lockdown phase (L).

Considering first $\mathrm{NO}_{2}$, the data of Table 3 show a generalized decrease in all stations when passing from the period corresponding to the pre-lockdown to the lockdown phase for both years but with a larger reduction in 2020 for the stations AO, NM and AS. In fact, the background station located in the green area of VP shows a variation of about $-50 \%$ in both years, indicating also in this case a seasonal trend probably related to residential heating. In the year 2019, a smaller decrease is observed for AO (-26\%), NM (-21\%) and AS (-20\%) since such sampling stations are located in suburban, urban and urban/industrial areas of the city that are affected by the traffic, vehicles exhaust and industrial processes favoring $\mathrm{NO}_{2}$ production. Interestingly, the reduction of $\mathrm{NO}_{2}$ is more than doubled in these areas in the year 2020 by passing from pre-lockdown to the lockdown phase for AO (-61\%), NM (-49\%) and AS (-51\%). Moreover, a direct comparison between the same periods in the two years clearly highlights a similar level of $\mathrm{NO}_{2}$ concentration in the period before lockdown and a drastic reduction by $\approx(45-50) \%$ for $A O, N M$ and $A S$ in the lockdown stage, whereas VP remains almost stationary. This observation, in turn, supports the scenario of a drastic contraction of $\mathrm{NO}_{2}$ pollution induced by the lockdown in the year 2020, in agreement with the indication provided by EU "Copernicus" satellites programme (EU Copernicus, 2020). Moreover, the level of reduction observed before and during lockdown is consistent with that observed in Barcelona (Tobías et al., 2020), Dehli (Mahato et al., 2020) and in central China (Xu et al., 2020a, b).

As for the other pollutants, CO seems to show similar levels between 2019 and 2020 before lockdown and a reduction in the lockdown phase. This reduction is more significant in NM and AS stations (> 50\%) that, according to the urban/industrial nature of these sampling sites, can be related to the limitation of traffic and industrial activity during lockdown phase, which induced a substantial reduction of $\mathrm{CO}$ emission due to automobile exhaust and industrial fossil fuel burning activities. $\mathrm{SO}_{2}$ shows a decreasing trend in the VP station with a concentration that is almost

Table 3. Mean values of $\mathrm{C}_{6} \mathrm{H}_{6}, \mathrm{CO}$ and $\mathrm{NO}_{2}$ concentration $\left(\mu \mathrm{g} \mathrm{m}^{-3}\right)$ registered by sampling stations located at the four reference city points (VP, AO, NM, AS) and $\mathrm{SO}_{2}\left(\mu \mathrm{g} \mathrm{m}^{-3}\right)$ for $\mathrm{VP}$ and $\mathrm{AS}$ in the period preceding the lockdown $(\mathrm{P})$ and during the lockdown $(\mathrm{L})$ phase for the years 2019 and 2020.

\begin{tabular}{|c|c|c|c|c|c|c|c|c|}
\hline \multirow{2}{*}{$\begin{array}{l}\text { Station } \\
\text { Period (P/L) }\end{array}$} & \multicolumn{2}{|c|}{ VP } & \multicolumn{2}{|c|}{$\mathrm{AO}$} & \multicolumn{2}{|c|}{ NM } & \multicolumn{2}{|c|}{ AS } \\
\hline & $\mathrm{P}$ & $\mathrm{L}$ & $P$ & $\mathrm{~L}$ & $\mathrm{P}$ & $\mathrm{L}$ & $\mathrm{P}$ & $\mathrm{L}$ \\
\hline \multicolumn{9}{|l|}{ Year 2019} \\
\hline $\mathrm{C}_{6} \mathrm{H}_{6}$ & $0.60 \pm 0.06$ & $0.60 \pm 0.06$ & $2.0 \pm 0.1$ & $1.2 \pm 0.1$ & $2.8 \pm 0.2$ & $1.3 \pm 0.1$ & $1.7 \pm 0.2$ & $0.4 \pm 0.04$ \\
\hline $\mathrm{CO}$ & $0.50 \pm 0.03$ & $0.30 \pm 0.02$ & $0.60 \pm 0.02$ & $0.50 \pm 0.01$ & $0.90 \pm 0.06$ & $0.70 \pm 0.03$ & $1.00 \pm 0.06$ & $0.80 \pm 0.02$ \\
\hline $\mathrm{NO}_{2}$ & $12 \pm 1$ & $5.6 \pm 0.6$ & $30 \pm 2$ & $22 \pm 2$ & $61 \pm 3$ & $48 \pm 3$ & $50 \pm 2$ & $40 \pm 2$ \\
\hline $\mathrm{SO}_{2}$ & $1.9 \pm 0.1$ & $1.0 \pm 0.1$ & - & - & - & - & $4.7 \pm 0.5$ & $4 \pm 1$ \\
\hline \multicolumn{9}{|l|}{ Year 2020} \\
\hline $\mathrm{C}_{6} \mathrm{H}_{6}$ & $0.6 \pm 0.3$ & $0.40 \pm 0.06$ & $1.0 \pm 0.1$ & $0.60 \pm 0.06$ & $1.4 \pm 0.1$ & $0.30 \pm 0.05$ & $1.4 \pm 0.2$ & $0.6 \pm 0.1$ \\
\hline $\mathrm{CO}$ & $0.20 \pm 0.04$ & $0.20 \pm 0.03$ & $0.50 \pm 0.03$ & $0.40 \pm 0.04$ & $1.0 \pm 0.1$ & $0.50 \pm 0.03$ & $1.2 \pm 0.1$ & $0.50 \pm 0.02$ \\
\hline $\mathrm{NO}_{2}$ & $10 \pm 1$ & $5.1 \pm 0.5$ & $26 \pm 2$ & $10 \pm 2$ & $51 \pm 2$ & $26 \pm 3$ & $45 \pm 2$ & $22 \pm 2$ \\
\hline $\mathrm{SO}_{2}$ & $3 \pm 1$ & $1.4 \pm 0.2$ & - & - & - & - & $4.4 \pm 0.2$ & $1.3 \pm 0.4$ \\
\hline
\end{tabular}


halved before and during lockdown in both years 2019 and 2020, but that diminishes by only $\approx 15 \%$ in 2019 and by $\approx 70 \%$ in 2020 in the industrial area sampled by AS station according to a reduction of coal and chemical fuels combustion derived by industrial activity restriction. Finally, Benzene $\left(\mathrm{C}_{6} \mathrm{H}_{6}\right)$ seems also to display a reduction trend by passing from before to during lockdown for both years. This reduction has a seasonal origin due to a major pollutant dilution during warm season rather than in winter. Moreover, it is partially ascribed to natural component due to local burning activities in the area surrounding Naples and decomposition of organic matter. A larger reduction is observed at NM urban station where Benzene diminishes by $\approx 50 \%$ in 2019 and by $\approx 80 \%$ in 2020 according to vehicular traffic and transportation reduction during lockdown period. The analysis illustrated above shows a significant variation of the registered pollutants in urban and industrial areas as a consequence of the restrictions to social and production activities that limited traffic and combustion processes in factories.

\subsection{Atmospheric Aerosol Characterization by CIMEL Sun-Sky-Lunar Photometer}

Ground level PM may not be fully representative of the aerosol present in the atmospheric column, which can be investigated by remote sensing (Brogniez et al., 2013; Tomasi et al., 2016). In an attempt to clarify possible effects of COVID-19 lockdown on the optical and microphysical columnar properties of aerosol above Naples, AERONET level 1.5 cloud-screened and qualitycontrolled sun-photometer data were analyzed. In particular, columnar aerosol optical depth $(A O D)$ at $440 \mathrm{~nm}$, Ångström exponent $(\alpha)$ obtained by the $870 \mathrm{~nm} / 440 \mathrm{~nm}$ ratio and volume particle size distribution, $\mathrm{dV}(\mathrm{r}) / \mathrm{d} \ln (\mathrm{r})$ (in $\mu \mathrm{m}^{3} \mu \mathrm{m}^{-2}$ ), measured from January to April 2020 were considered gaining insights on atmospheric aerosol properties as well as on the relative influence of coarse versus fine mode aerosol (Reid et al., 1999). AOD and $\alpha$ daily mean values were retrieved for 36 days from the sun-photometer measurements carried out during January and March 2020 (hereafter indicated as "solar" data). In order to overcome a lack of level 1.5 data for the months of February and April 2020, lunar provisional products corresponding to 46 days of measurements were also considered (hereafter identified as "lunar" data). These data have been grouped in two different classes corresponding to the time interval preceding the lockdown $(\mathrm{P})$ and to the lockdown period $(\mathrm{L})$ with the aim of highlighting possible changes occurred in the aerosol properties.

Daily AOD values range from 0.08 to 0.5 (solar) and from 0.04 to 0.62 (lunar) with mean values of $(0.22 \pm 0.01)$ and $(0.22 \pm 0.02)$, respectively. $\alpha$ values range from 0.9 to 1.9 (solar) and from 0.03 to 1.8 (lunar) with mean values of $(1.51 \pm 0.05)$ and $(1.17 \pm 0.07)$, respectively. These values of the aerosol parameters are consistent with those typically observed in the Mediterranean region (Boselli et al., 2012; Mallet et al., 2016).

Figs. 3 and 4 report the histograms of the values of AOD and $\alpha$ as obtained from solar and lunar data corresponding to the lockdown (panels (a) and (c)) and pre-lockdown phases (panels (b) and (d)). Considering first AOD, one can observe a shift towards larger values during lockdown. In particular, the average AOD value increases from $(0.20 \pm 0.01)$ to $(0.26 \pm 0.03)$ for the solar data with a variation of $\sim 30 \%$, whereas a more marked deviation occurs for the lunar data with average AOD increasing by about a factor 2 rising from $(0.17 \pm 0.01)$ to $(0.32 \pm 0.04)$. This observation can be likely ascribed to a more important contribution of SD transport events typically occurring in the period of the year corresponding to the lockdown in 2020 as demonstrated by three years systematic lidar measurements over Naples indicating that $~ 70 \%$ of the SD events occur in the spring/summer period (Pisani et al., 2011). As for the histogram of $\alpha$, Fig. 4 highlights the presence of lower values of the parameter in the histogram corresponding to night-time conditions (panels (c) and (d)). Differences in the aerosol dimension could be due to change in the size distribution due to coagulation, humidification and gas-to-particle conversion (Kaskaoutis et al., 2006; Biskos et al., 2009). However, the average values of $\alpha$ remains almost unchanged passing from the pre-lockdown to the lockdown phase with variations from (1.53 \pm 0.06$)$ to (1.46 $\pm 0.08)$ and from $(1.1 \pm 0.1)$ to $(1.3 \pm 0.1)$ for the solar and lunar measurements, respectively.

In order to highlight possible changes in the anthropogenic component of the atmospheric aerosol and try distinguishing anthropic contribution to the total columnar properties related to local background condition, we separated the data corresponding to SD transport over the 

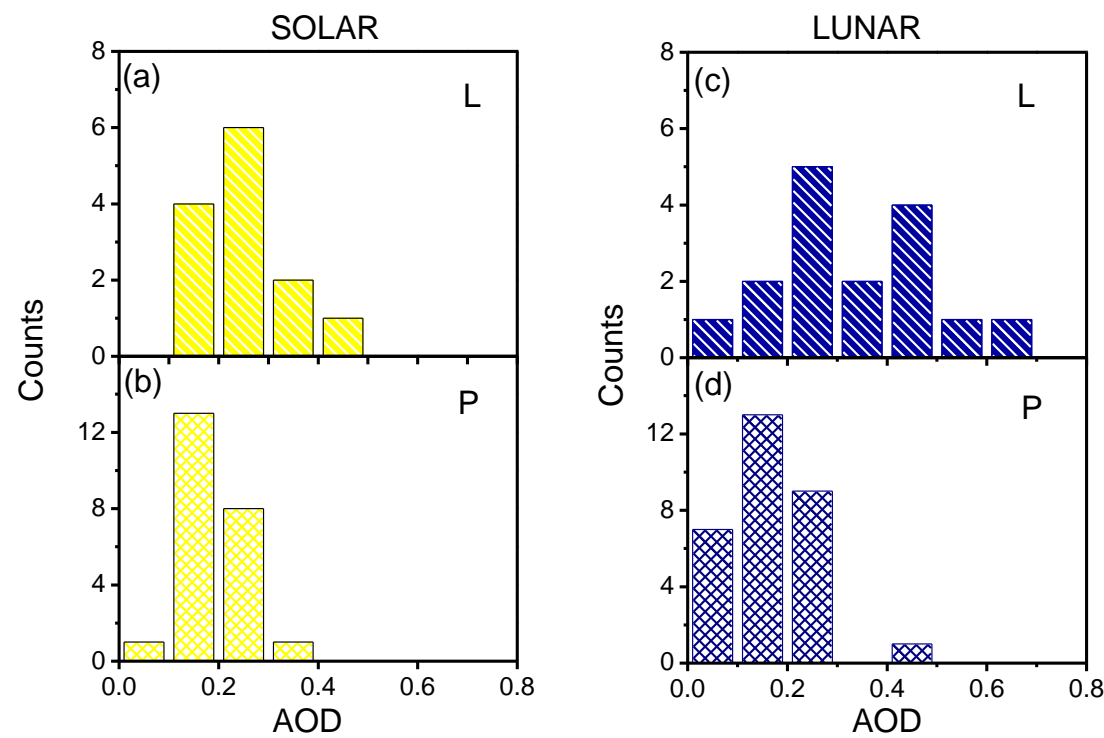

Fig. 3. AOD count distributions. Panels (a) and (b) report the histograms of solar data for the Lockdown and Pre-lockdown periods, respectively. Panels (c) and (d) display the histograms of lunar data for the Lockdown and Pre-lockdown periods, respectively.
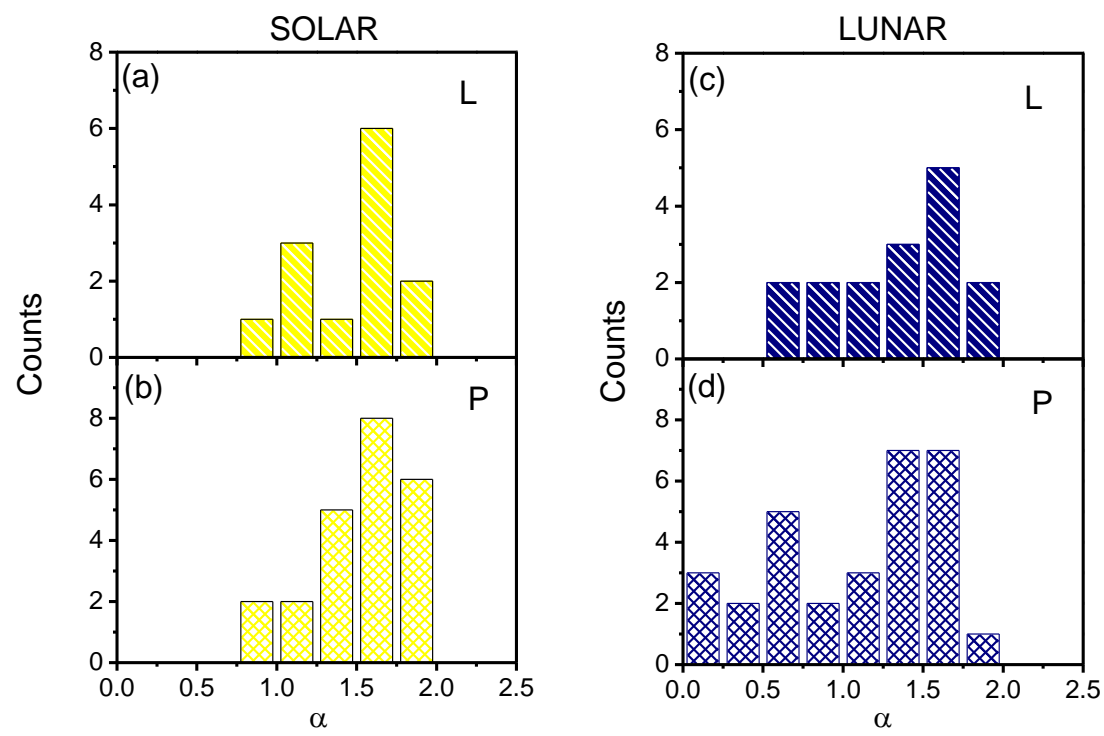

Fig. 4. $\alpha$ count distributions. Panels (a) and (b) report the histograms of solar data for the Lockdown and Pre-lockdown periods, respectively. Panels (c) and (d) display the histograms of lunar data for the Lockdown and Pre-lockdown periods, respectively.

measurement area from those with no SD events (NSD), referring the last ones more directly to local anthropogenic contributions. Moreover, for the sake of comparison, we also considered data for the year 2019 in the same period of the year. The mean values of AOD and $\alpha$ are summarized in the Table 4.

As for the SD data, mean values of the parameters AOD and $\alpha$ result comparable within the uncertainty in most of the cases, therefore evidencing no clear variations between pre-lockdown and lockdown phases in both solar and lunar measurements, for both years. The mean values of AOD in the range $0.2-0.3$ and of $\alpha$ around 1 are suggestive of the occurrence of moderate dust events over the whole period with a predominance of a coarse mode aerosol fraction. Instead, year 2020 NSD data display a larger variability with a rise of the average AOD value within the lockdown phase that is more pronounced for measurements carried out in night-time, with an increase of $\approx 30 \%$ and $\approx 100 \%$ for solar and lunar cases, respectively. The observed increase of the 
Table 4. Mean values of $A O D$ and $\alpha$ registered by solar and lunar measurements in the period preceding the lockdown ( $P$ ) and during the lockdown (L) phases for the years 2019 and 2020.

\begin{tabular}{|c|c|c|c|c|c|c|c|c|}
\hline \multirow{3}{*}{ Period (P/L) } & \multicolumn{4}{|c|}{ Saharan Dust } & \multicolumn{4}{|c|}{ No Saharan Dust } \\
\hline & \multicolumn{2}{|c|}{ Year 2019} & \multicolumn{2}{|c|}{ Year 2020} & \multicolumn{2}{|c|}{ Year 2019} & \multicolumn{2}{|c|}{ Year 2020} \\
\hline & $\mathrm{P}$ & $\mathrm{L}$ & $\mathrm{P}$ & $\mathrm{L}$ & $\mathrm{P}$ & $\mathrm{L}$ & $\mathrm{P}$ & $\mathrm{L}$ \\
\hline & & & & & & & & \\
\hline \multirow[t]{3}{*}{ AOD } & $0.18 \pm 0.01$ & $0.22 \pm 0.01$ & $0.27 \pm 0.09$ & $0.26 \pm 0.04$ & $0.12 \pm 0.01$ & $0.18 \pm 0.02$ & $0.19 \pm 0.01$ & $0.24 \pm 0.04$ \\
\hline & $1.0 \pm 0.2$ & $1.3 \pm 0.1$ & $0.97 \pm 0.05$ & $1.4 \pm 0.1$ & $1.5 \pm 0.1$ & $1.4 \pm 0.1$ & $1.62 \pm 0.04$ & $1.5 \pm 0.1$ \\
\hline & \multicolumn{8}{|c|}{ Lunar } \\
\hline \multirow[t]{2}{*}{ AOD } & $0.3 \pm 0.1$ & $0.3 \pm 0.1$ & $0.21 \pm 0.03$ & $0.29 \pm 0.07$ & $0.18 \pm 0.04$ & $0.19 \pm 0.02$ & $0.17 \pm 0.02$ & $0.34 \pm 0.03$ \\
\hline & $1.2 \pm 0.2$ & $0.8 \pm 0.2$ & $1.1 \pm 0.3$ & $1.3 \pm 0.1$ & $1.3 \pm 0.1$ & $1.3 \pm 0.1$ & $1.1 \pm 0.1$ & $1.71 \pm 0.04$ \\
\hline
\end{tabular}

AOD during lockdown can be ascribed to meteorological effects, such as reduced rainfall and higher temperature registered in this period, that slow pollutants dispersion in the atmosphere (Broomandi et al., 2020). Moreover, a lower Planetary Boundary Layer height during nighttime can explain the larger increase observed for the lunar cases. Conversely, no similar variation is clear in NSD data of the year 2019. Moreover, while in 2019 no changes are observed in the mean values of $\alpha$ both for sun and lunar measurements, a rather significant variation occurs again in the lunar case with mean value larger than 1.5 during lockdown. These observations are suggestive of a change in the aerosol characteristics during lockdown revealing a dominance of fine mode aerosol in the atmospheric column not directly associated with the typical contributions of natural dust but more likely related other local source of pollution. Interestingly, the increase of the AOD seems to contrast with the reduction of PM measured at the ground. Therefore, to gain further insights on aerosol features and a clearer interpretation of the data an additional analysis was carried out by contrasting the two aerosol parameters AOD and $\alpha$, as reported hereafter. In fact, the relationship between these two parameters allows explaining how aerosol load depends on particle size as well as defining different aerosol typologies on the base of their different optical properties (Valenzuela et al., 2014). Fig. 5 reports scatter plots of $\alpha$ vs AOD for solar and lunar measurements, respectively, for both years 2020 and 2019. In the panels of Fig. 5, data corresponding to pre-lockdown are shown as yellow circles and blue stars, whereas those of the lockdown period are displayed as black circles and stars. The comparison between panels clearly demonstrates that during the lockdown in year 2020 there is a lack of data points within the shaded regions of the plots characterized by values of the parameters ( $A O D \leq 0.2 ; \alpha \leq 1.5$ ) for the solar observations (panels (a) and (b)) and (AOD $\leq 0.2 ; \alpha \leq 1$ ) for the lunar measurements (panels $(c)$ and $(d))$, respectively. These regions of the space of parameters (AOD, $\alpha$ ) correspond to atmospheric conditions characterized by large particles, generally associated to local soil particle up-lift and polluted marine aerosol components, and large and fine anthropogenic particles, associated to emissions produced by vehicular motion and anthropogenic activities (Toledano et al., 2007; Pavese et al., 2016). Therefore, the absence of data in the area of the space of parameters observed in Fig. 5 suggests a reduction of aerosol of anthropogenic origin. This, in turn, led to a more important contribution along the atmospheric column of fine mode aerosol with respect to coarse particles in clearer atmospheric conditions. The aerosol present in the atmospheric column could be associated to continental origin and more or less polluted marine components. Moreover, the closeness to the Solfatara natural source of $\mathrm{SO}_{2}$ could also contribute to sub-micron secondary sulphate aerosol in the atmosphere.

Typically, atmospheric aerosol exhibits a bimodal size distribution and the particles are classified in fine (diameter $<1 \mu \mathrm{m}$ ) and coarse (diameter $>1 \mu \mathrm{m}$ ) mode aerosol on the base of their radius or diameter. The aerosol size distribution depends on local sources and on long range transport phenomena, that in the Mediterranean regions are mainly responsible for large dust aerosol in the atmosphere. Analysis of the columnar volume particle size distribution $d V(r) / d \ln (r)$ can highlight size features of the aerosol still more clearly. Therefore, we have selected all the AERONET size distributions acquired at Naples-CeSMA site in the period of year 2020 under investigation as well as for the same temporal range of the previous year 2019 . With the aim of highlighting any possible influence of the local sources on the aerosol size distribution during lockdown, columnar size distribution obtained for the pre-lockdown and lockdown periods in the 

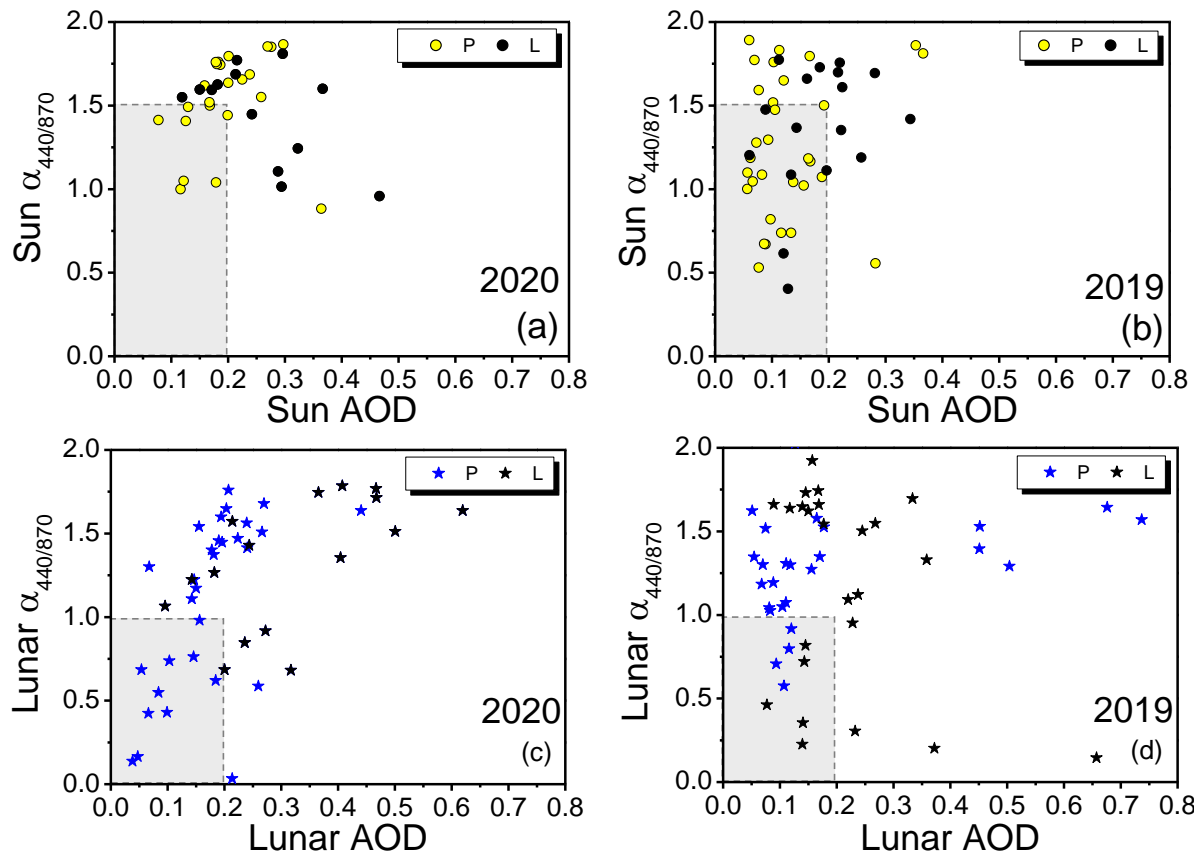

Fig. 5. Scatter plots of $\alpha$ vs. AOD for solar and lunar measurements. Panels (a) and (b) report solar data for the Lockdown (black circles) and Pre-lockdown (yellow circles) periods, respectively. Panels (c) and (d) display lunar data for the Lockdown (black stars) and Pre-lockdown (blue stars) periods, respectively.

year 2020 and in absence of Saharan Dust effects are analyzed and contrasted with size distribution corresponding to the year 2019. The columnar volume particle size distribution data collected day by day show a variable number of distributions; therefore, size distribution averaged over 24 hours were considered. Discarding distributions affected by Saharan dust, we used 11 and 20 profiles for the pre-lockdown period and 4 and 19 profiles for the lockdown period for the years 2020 and 2019, respectively. The mean standard deviation was chosen as uncertainty for the data. Results for the year 2020 are reported in Fig. 6, whereas the distributions associated to pre-lockdown and lockdown periods for the year 2019 (not shown) do not evidence changes besides expected seasonal fluctuations reported in the literature (Liu et al., 2011; Dinoi et al., 2020). Fig. 6 reports the columnar volume particle size distributions for year 2020 without (panel (a) - NSD) and with the influence of Saharan dust (panel (b) -SD) events. Panel (a) of Fig. 6 evidences a difference between pre-lockdown and lockdown aerosol features in absence of SD, confirming a larger predominance of fine particulates in the atmospheric column during lockdown. The increased contribution of fine aerosol is combined with a similar content in coarse mode aerosol for NSD. On the other hand, panel (b) of Fig. 6 reporting the distributions corresponding to SD events shows a larger contribution of aerosol in coarse mode fraction along the atmospheric column with respect to panel (a), both for the pre-lockdown and lockdown phases. In this second case, both distribution show similar characteristics within the uncertainty. This distribution is typically observed in the Mediterranean basin when desert dust is mixed with maritime and local tropospheric aerosols (Fotiadi et al., 2006; Boselli et al., 2012; Sicart et al., 2016). The analysis of the sun photometer measurements reported above highlights an interesting variation of atmospheric aerosol composition in the lockdown with a reduction of coarse mode aerosol component. This observation can be likely associated to a decrease of the particulate produced due to vehicular motion and anthropogenic activities evidenced by the PM reduction at the ground.

\section{CONCLUSIONS}

The spread of COVID-19 pandemic over Europe and Italy in the beginning of March 2020 

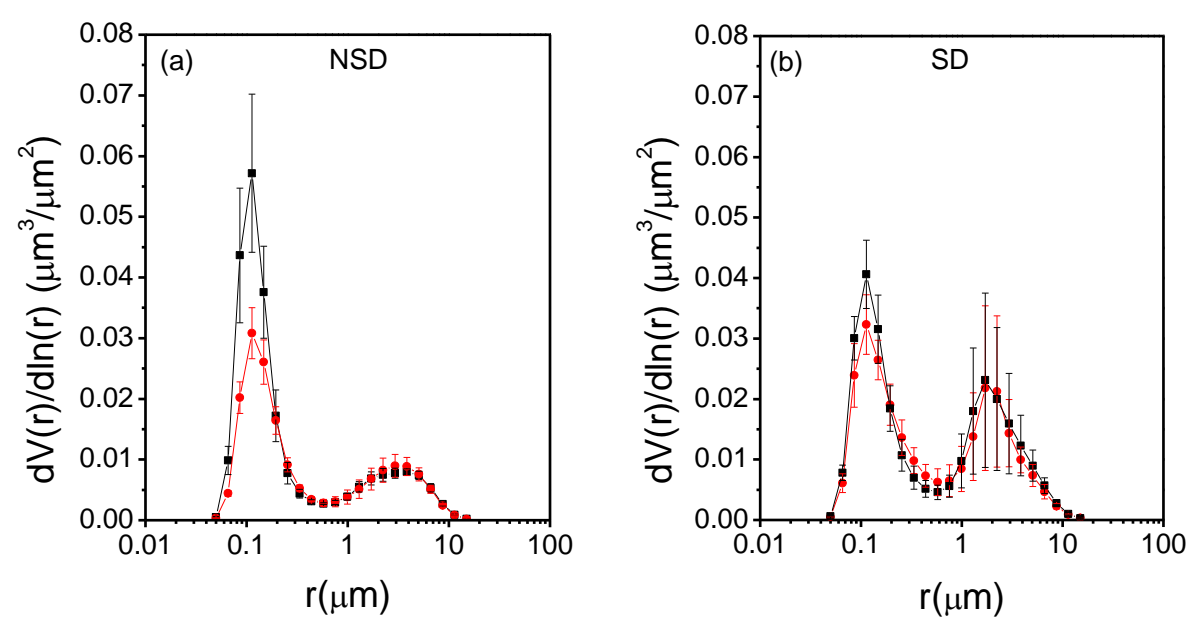

Fig. 6. Columnar volume particle size distribution $d V(r) / d \ln (r)$ for year 2020 separated for the cases without (panel (a) - NSD) and with the influence of Saharan dust (panel (b) - SD) events. The two profiles in each panel refer to pre-lockdown (red circles) and lockdown (black squares) respectively.

strongly restricted human social and industrial activities. These limitations were mainly aimed at contrasting the epidemic diffusion by imposing people confinement, but public transport and economic activity reduction or halting were accompanied by a sizeable diminution of vehicles traffic and industrial production. A variation of the urban air pollution levels was consequently expected. Here we aimed at investigating changes in air quality in the city of Naples during the implementation of the lockdown measures. Both ground level and atmospheric remote sensing approaches were used to gain information on the effects of lockdown. Ground level measurements from four reference air quality stations located in various points in the City of Naples allowed assessing the levels of $\mathrm{C}_{6} \mathrm{H}_{6}, \mathrm{CO}, \mathrm{NO}_{2}$, and $\mathrm{SO}_{2}$, as well as of $\mathrm{PM}_{2.5}$ and $\mathrm{PM}_{10}$. Particulate matter analysis was also complemented by measurements carried out by an Optical Particles Counter operative at our laboratory in the University Campus. Moreover, columnar properties of the atmospheric aerosol were gathered by using data provided by an AERONET sun photometer operational at our University. Aerosol and particulate matter were analyzed tacking into account the possible influence of Saharan Dust events characterizing our region and the entire Mediterranean area.

Our findings evidence a drastic reduction of $\mathrm{NO}_{2}$, accompanied by a comparable change in $\mathrm{CO}$ and $\mathrm{SO}_{2}$, in urban and industrial areas of the city, whereas very limited effects occurred for reference location like urban green areas. Instead, the variation of PM was more limited. Sun photometer measurements evidence an increase of the atmospheric AOD in the lockdown period that seems to contrast with the reduction of PM concentration at ground observed in the urban and industrial areas. Hence, a further analysis of the atmospheric aerosol was carried out that evidenced an interesting variation of its composition with a reduction of coarse mode aerosol component during the lockdown, likely associated to a decrease of particulate produced by vehicular motion and anthropogenic activities, in fairly good agreement with the observed PM reduction at the ground.

These experimental findings offer a remarkable view on air quality issues in the rather unique situation caused by lockdown that might be very relevant to ascertain anthropogenic influences on air quality to develop better strategies for the control of the city environmental conditions.

\section{ACKNOWLEDGMENTS}

The activities have received funding from the European Union's Horizon 2020 research and innovation programme under grant agreement No 654109, ACTRIS2 project.

The authors gratefully acknowledge the NOAA Air Resource Laboratory (ARL) for provision the HYSPLIT transport and dispersion model and /or READY website used in this publication. Data 
and/or from the BSC-DREAM8b (Dust Regional Atmospheric Model) model were operated by the Barcelona Supercomputing Center (http://www.bsc.es/ess/bsc-dust-daily-forecast/).

The authors also acknowledge ARPAC for providing atmospheric air pollution data. Additional thanks are addressed to the I-AMICA Project - Italian National Operation Program "Ricerca e Competitività" (Research and Competitiveness) 2007-2013 (PON “R\&C").

\section{REFERENCES}

Amato, F., Alastuey, A., Karanasiou, A., Lucarelli, F., Nava, S., Calzolai, G., Severi, M., Becagli, S., Gianelle, V.L., Colombi, C., Alves, C., Custódio, D., Nunes, T., Cerqueira, M., Pio, C., Eleftheriadis, K., Diapouli, E., Reche, C., Minguillón, M.C., ... Querol, X. (2016). AIRUSE-LIFEC: A harmonized PM speciation and source apportionment in five southern European cities. Atmos. Chem. Phys. 16, 3289-3309. https://doi.org/10.5194/acp-16-3289-2016

ARPAC (2020). www.arpacampania.it

Biskos, G., Buseck, P.R., Martin, S.T. (2009). Hygroscopic growth of nucleation mode acidic sulfate particles. J. Aerosol Sci. 40, 338-347. https://doi.org/10.1016/j.jaerosci.2008.12.003

Boselli, A., Caggiano R., Cornacchia C., Madonna F., Macchiato, M., Mona, L., Pappalardo, G, Trippetta, S. (2012). Multi year sun-photometer measurements for aerosol characterization in a Central Mediterranean site. Atmos. Res. 104-105, 98-110. https://doi.org/10.1016/j.atmosr es.2011.08.002

Brogniez, C., Lenoble, J., Shaw, G. (2013). Direct observation of the sun for aerosol retrieval. in: Lenoble, J., Remer, L., Tanre, D. (Eds.), Aerosol remote sensing. Springer, Berlin, Heidelberg, pp. 87-99. https://doi.org/10.1007/978-3-642-17725-5_4

Broomandi, P., Karaca, F., Nikfal, A., Jahanbakhshi, A., Tamjidi, M., Kim, J.R. (2020). Impact of COVID-19 event on the air quality in Iran. Aerosol Air Qual. Res. 20, 1793-1804. https://doi.org/10.4209/aaqr.2020.05.0205

Chameides, W.L., Fehsenfeld, F., Rodgers, M.O., Cardelino, C., Martinez, J., Parrish, D., Lonneman, W., Lawson, D.R., Rasmussen, R.A., Zimmerman, P., Greenberg, J., Middleton, P., Wang, T. (1992). Ozone precursor relationships in the ambient atmosphere. J. Geophys. Res. 97, 60376055. https://doi.org/10.1029/91JD03014

Dinoi, M., Conte, M., Grasso, F.M., Contini, D. (2020). Long-Term characterization of submicron atmospheric particles in an urban background site in Southern Italy. Atmosphere 11, 334-349. https://doi.org/10.3390/atmos11040334

Dubovik, O., King, M.D. (2000). A flexible inversion algorithm for the retrieval of aerosol optical properties from sun and sky radiance measurements. J. Geophys. Res. 105, 20673-20696. https://doi.org/10.1029/2000JD900282

European Union (EU) (2020). Copernicus Program - European Air Quality information in support of the COVID-19 crisis. https://atmosphere.copernicus.eu/european-air-quality-information-supportcovid-19-crisis?utm_source=social_media\&utm_medium=posts\&utm_campaign=COVID19

Faridi, S., Yousefian, F., Niazi, S., Ghalhari, M.R., Hassanvand, M.S., Naddafi, K. (2020). Impact of SARS-CoV-2 on ambient air particulate matter in Tehran. Aerosol Air Qual. Res. 20, 1805-1811. https://doi.org/10.4209/aaqr.2020.05.0225

Filonchyk, M., Hurynovich, V., Yan, H., Gusev, A., Shpilevskaya, N. (2020). Impact assessment of COVID-19 on Variations of $\mathrm{SO}_{2}, \mathrm{NO}_{2}, \mathrm{CO}$ and $\mathrm{AOD}$ over East China. Aerosol Air Qual. Res. 20: 1530-1540. https://doi.org/10.4209/aaqr.2020.05.0226

Fotiadi, A., Hatzianastassiou, N., Drakakis, E., Matsoukas, C., Pavlakis, K.G., Hatzidimitriou, D., Gerasopoulos, E., Mihalopoulos, N., Vardavas, I. (2006). Aerosol physical and optical properties in the Eastern Mediterranean Basin, Crete, from Aerosol Robotic Network data. Atmos. Chem. Phys. 6, 5399-5413. https://doi.org/10.5194/acp-6-5399-2006

Giles, D.M., Sinyuk, A., Sorokin, M.G., Schafer, J.S., Smirnov, A., Slutsker, I., Eck, T.F., Holben, B.N., Lewis, J.R., Campbell, J.R., Welton, E.J., Korkin, S.V., Lyapustin, A.I. (2019). Advancements in the Aerosol Robotic Network (AERONET) Version 3 database - automated near-real-time quality control algorithm with improved cloud screening for Sun photometer aerosol optical depth (AOD) measurements. Atmos. Meas. Tech. 12, 169-209. https://doi.org/10.5194/amt12-169-2019 
Holben, B.N., Eck, T.F., Slutsker, I., Tanré, D., Buis, J.P., Setzer, A., Vermote, E., Reagan, J.A., Kaufman, Y.J., Nakajima, T., Lavenu, F., Jankowiak, I., Smirnov, A. (1998). AERONET-a federated instrument network and data archive for aerosol characterization. Remote Sens. Environ. 66, 1-16. https://doi.org/10.1016/S0034-4257(98)00031-5

Holben, B.N., Tanré, D., Smirnov, A., Eck, T.F., Slutsker, I., Abuhassan, N., Newcomb, W.W., Schafer, J., Chatenet, B., Lavenue, F., Kaufman, Y.J., Vande Castle, J., Setzer, A., Markham, B., Clark, D., Frouin, R., Halthore, R., Karnieli, A., O'Neill, N.T., ... Zibordi, G. (2001). An emerging ground-based aerosol climatology: aerosol optical depth from AERONET. J. Geophys. Res. 106, 12067-12097. https://doi.org/10.1029/2001JD900014

Kaskaoutis, D.G., Kambezidisa, H.D, Adamopoulosb, A.D., Kassomenos, P.A. (2006). On the characterization of aerosols using the Ångström exponent in the Athens area. J. Atmos. Sol. Terr. Phys. 68, 2147-2163. https://doi.org/10.1016/j.jastp.2006.07.008

Liu, J., Zheng, Y., Li, Z., Flynn, C., Cribb, M. (2012). Seasonal variations of aerosol optical properties, vertical distribution and associated radiative effects in the Yangtze Delta region of China. J. Geophys. Res. 117, D00K38. https://doi.org/10.1029/2011JD016490

Mahato, S., Pal, S., Ghosh, K.G. (2020). Effect of lockdown amid COVID-19 pandemic on air quality of the megacity Delhi, India. Sci. Total Environ. 730, 139086. https://doi.org/10.1016/j.scitote nv.2020.139086

Mallet, M., Dulac, F., Formenti, P., Nabat, P., Sciare, J., Roberts, G., Pelon, J., Ancellet, G., Tanré, D., Parol, F., Denjean, C., Brogniez, G., di Sarra, A., Alados-Arboledas, L., Arndt, J., Auriol, F., Blarel, L., Bourrianne, T., Chazette, P., ... Zapf, P. (2016). Overview of the chemistry-aerosol Mediterranean experiment/aerosol direct radiative forcing on the Mediterranean Climate (ChArMEx/ADRIMED) summer 2013 campaign. Atmos. Chem. Phys. 16, 455-504. https://doi.org/10.5194/acp-16-455-2016

Nakada, L.Y.K., Urban, R.C. (2020). COVID-19 pandemic: Impacts on the air quality during the partial lockdown in São Paulo state, Brazil. Sci. Total Environ. 730, 139087. https://doi.org/10.1 016/j.scitotenv.2020.139087

Pavese, G., Lettino, A, Calvello, M., Esposito, F., Fiore, S. (2016). Aerosol composition and properties variation at the ground and over the column under different air masses advection in South Ital. Environ. Sci. Pollut. Res. 23, 6546-6562. https://doi.org/10.1007/s11356-0155860-1

Pisani, G., Boselli, A., Spinelli, N., Wang, X. (2011). Characterization of Saharan dust layers over Naples (Italy) during 2000-2003 EARLINET project. Atmos. Res. 102, 286-299. https://doi.org/1 0.1016/j.atmosres.2011.07.012

Reid, J.S., Eck, T.F., Christopher, S.A., Hobbs, P.V., Holben, B.N. (1999). Use of the Ångström exponent to estimate the variability of optical and physical properties of aging smoke particles in Brazil. J. Geophys. Res. 104, 27473-27489. https://doi.org/10.1029/1999JD900833

Sharma, S., Zhang, M., Anshika, Gao, J., Zhang, H., Kota, S.H. (2020). Effect of restricted emissions during COVID-19 on air quality in India. Sci. Total Environ. 728, 138878. https://doi.org/10.101 6/j.scitotenv.2020.138878

Sicart, M., Barragan, R., Dulac, F., Alados-Arboledas, L., Mallet, M. (2016). Aerosol optical, microphysical and radiative properties at regional background insular sites in the western Mediterranean. Atmos. Chem. Phys. 16, 12177-12203. https://doi.org/10.5194/acp-16-121772016

Sillman, S. (1999). The relation between ozone, $\mathrm{NO}_{x}$ and hydrocarbons in urban and polluted rural environments. Atmos. Environ. 33, 1821-1845. https://doi.org/10.1016/S1352-2310(98)00345-8

Taylor, J.R. (2018) An introduction to error analysis, 2nd Edition. University Science Books. Sausalito.

Tobías, A., Carnerero, C., Reche, C., Massagué, J., Via, M., Minguillón, M.C., Alastuey, A., Querol, $X .(2020)$. Changes in air quality during the lockdown in Barcelona (Spain) one month into the SARS-CoV-2 epidemic. Sci. Total Environ. 726, 138540. https://doi.org/10.1016/j.scitotenv.202 0.138540

Toledano, C., Cachorro, V.E., Berjon, A., de Frutos, A.M., Sorribas, M., de la Morena, B.A., Goloub, P. (2007). Aerosol optical depth and Ångström exponent climatology at El Arenosillo AERONET site (Huelva, Spain). Q.J. R. Meteorol. Soc. 133, 795-807. https://doi.org/10.1002/qj.54

Tomasi, C., Fuzzi, S., Kokhanovsky, A. (2016). Atmospheric aerosols - Life cycles and effects on air 
quality and climate. Wiley-VCH Verlag GmbH \& Co. Weinheim, Germany.

Valenzuela, A., Olmo, F.J., Lyamani, H., Granados-Muñoz, M. J., Antón, M., Guerrero-Rascado, J.L., Quirantes, A., Toledano, C., Perez-Ramírez, D., Alados-Arboledas, L. (2014). Aerosol transport over the western Mediterranean basin: Evidence of the contribution of fine particles to desert dust plumes over Alborán Island. J. Geophys. Res. 119, 14028-14044. https://doi.org/10.1002/2014JD022044

Xu, K., Cui, K., Young, L.H., Wang, Y.F., Hsieh, Y.K., Wan, S., Zhang, J. (2020a). Air quality index indicatory air pollutants and impact of COVID-19 event on the air quality near central China. Aerosol Air Qual. Res. 20, 1204-1221. https://doi.org/10.4209/aaqr.2020.04.0139

Xu, K., Cui, K., Young, L.H., Y.K. Hsieh, Y.K., Wang, Y.F., Zhang, J. Wan, S. (2020b). Impact of the COVID-19 event on air quality in central China. Aerosol Air Qual. Res. 20, 915-929. https://doi.org/10.4209/aaqr.2020.04.0150

Zambrano-Monserrate, M.A., Ruano, M.A., Sanchez-Alcalde, L. (2020). Indirect effects of COVID19 on the environment: Sci. Total Environ. 728, 138813. https://doi.org/10.1016/j.scitotenv.20 20.138813 